\title{
Fatores Humanos e Condições de Trabalho em Atividades de Implantação e Manutenção Florestal
}

\author{
Pedro Caldas Britto ${ }^{1}$, Eduardo da Silva Lopes ${ }^{1}$, \\ Carlos Henrique Fonseca Drinko ${ }^{1}$, Saulo Boldrini Gonçalves ${ }^{1}$
}

${ }^{1}$ Departamento de Engenharia Florestal, Universidade Estadual do Centro-Oeste - UNICENTRO, Irati/PR, Brasil

\begin{abstract}
RESUMO
Este trabalho objetivou avaliar os fatores humanos e as condições de trabalho em atividades de implantação e manutenção florestal visando subdiar a melhoria das condições de conforto, segurança e saúde dos trabalhadores. O estudo foi realizado em uma empresa florestal da Região dos Campos Gerais, estado do Paraná. A caracterização dos fatores humanos e das condições de trabalho foi realizada por meio de questionários aplicados na forma de entrevistas com 72 trabalhadores que atuavam em atividades silviculturais. De acordo com os resultados, a idade média dos trabalhadores foi de 34,9 anos, sendo a maioria de origem rural, casados, com baixo nível de escolaridade e com pouco tempo de experiência na empresa e na função, representados por 14,9 e 12,5 meses, respectivamente. Na opinião da maioria dos trabalhadores, os óculos de proteção utilizados na aplicação de herbicidas foram apontados como maiores causadores de desconforto no trabalho.
\end{abstract}

Palavras-chave: condições de trabalho, saúde ocupacional, ergonomia.

\section{Human Factors and Work Conditions in Forest Maintenance and Planting Operations}

\begin{abstract}
The objective of the present study was to evaluate the human factors and working conditions in forestry maintenance and planting operations in order to improve comfort, safety and health conditions of workers. The study was conducted in a forest company located in the region of Campos Gerais, Parana State. The characterization of human factors and work conditions was conducted by interviews with 72 workers of syilviculture activities. The results indicated that the workers' average age was 34.9 years, most of them from rural origin, married, with low level of education, and short time experience in the company and the function, 14.9 and 12.5 months, respectively. In the opinion of most of the workers, the protection glasses used in the herbicide application activity were identified as a cause of discomfort at work.
\end{abstract}

Keywords: work conditions, occupational health, ergonomics. 


\section{INTRODUÇÃO}

Apesar do processo de evolução ocorrida no setor florestal nos últimos anos, principalmente nas atividades de colheita da madeira que utiliza-se de máquinas e equipamentos de elevada tecnologia e produtividade, as atividades de implantação e manutenção são ainda, na maioria das empresas, realizadas por meio de métodos manuais ou semimecanizados e com grande contingente de mão de obra, atuando em condições adversas ao bem-estar, à segurança e à saúde.

Nesse contexto surge a ergonomia, que segundo Iida (2005) é o conjunto de conhecimentos a respeito do desempenho do ser humano na execução do trabalho, a fim de aplicá-los na concepção das tarefas, dos instrumentos, das máquinas e dos sistemas de produção. A ergonomia tem ainda contribuído para a melhoria das condições de trabalho do ser humano, sendo que em muitos países trata-se de um conceito relativamente novo e com contribuição ainda pequena em razão do baixo número de estudos e da restrita divulgação dos seus benefícios para o trabalhador (Fontana \& Seixas, 2007; Minetti et al., 1998).

Moreira (2009) diz que o trabalhador deve ser considerado como o capital humano da empresa e parte integrante e interdependente de todo o sistema produtivo. Por isso, para que as organizações possam alcançar o sucesso, devem buscar constantemente propostas para a melhoria das condições de trabalho e da satisfação do trabalhador. Já Massad et al. (2011) afirmam que a adaptação do homem ao trabalho é bastante complexa, sendo que a ergonomia poderá contribuir a partir do conhecimento do ser humano, projetando o ambiente de trabalho e ajustando-o às suas capacitações e limitações.

Por isso, na realização de uma análise ergonômica é importante iniciar pelo levantamento dos fatores humanos e das condições de trabalho, o que permite conhecer o perfil dos trabalhadores e identificar as condições de realização do trabalho. Com isso, muitas medidas poderão ser adotadas objetivando o aperfeiçoamento dos métodos e das técnicas de trabalho, assegurando condições mais confortáveis, seguras e saudáveis ao ser humano e, consequentemente, aumentando a produtividade e a qualidade do trabalho (Sant'anna \& Malinovski, 2002; Fiedler, 1998; Minetti, 1996; Grandjean, 1982).
Sant'Anna \& Malinovski (2002) comentam ainda sobre a importância do levantamento dos fatores humanos e das condições de trabalho, possibilitando que a área de trabalho, o seu arranjo, os equipamentos e as ferramentas sejam bem adaptados às capacidades psicofisiológicas, antropométricas e biomecânicas dos trabalhadores. Já Lopes (1996) considera que o estudo dos fatores humanos e das condições de trabalho auxiliará na implantação de novas técnicas de treinamento, melhorando a satisfação dos trabalhadores e evitando mudanças constantes de função na empresa.

$\mathrm{O}$ estudo dos fatores humanos consiste no levantamento do perfil do trabalhador, analisando-se variáveis como: estado civil, número de filhos, idade, escolaridade, origem, tempo de trabalho na empresa e na função, variáveis antropométricas etc. Já as condições de trabalho consistem no levantamento de informações que influenciam diretamente na satisfação do trabalhador na execução do trabalho e que afetam as condições de segurança, saúde, produtividade e a manutenção do sistema ser humano/máquina em funcionamento (Minetti, 1996; Fiedler, 1998).

Portanto, fica evidente a necessidade de realização de estudos sobre os fatores humanos e as condições de trabalho no setor florestal, principalmente nas atividades de implantação e manutenção, que envolvem um grande contingente de mão de obra que, normalmente, atua em atividades com baixo grau de mecanização e em condições ergonômicas inadequadas.

Este trabalho objetivou avaliar os fatores humanos e as condições de trabalho nas atividades de implantação e manutenção florestal, fornecendo informações para a reorganização ergonômica do trabalho e a melhoria das condições de conforto, saúde e segurança dos trabalhadores.

\section{MATERIAL E MÉTODOS}

\section{1. Área de estudo}

O trabalho foi desenvolvido a partir de dados coletados em áreas de implantação e manutenção de Eucaliptus spp. de uma empresa prestadora de serviços florestais, localizada na Região dos Campos Gerais, estado do Paraná.

O clima predominante da região de estudo, segundo a classificação de Köppen, é o subtropical - Cfa, com 
temperatura média anual no mês mais frio inferior a $18^{\circ} \mathrm{C}$ e temperatura média no mês mais quente acima de $22^{\circ} \mathrm{C}$, enquanto o relevo era diversificado, com áreas planas a fortemente onduladas e declividade variando de 0 a 45\% (IBGE, 2013).

\subsection{Atividades estudadas}

Foram estudadas as atividades de plantio, adubação e aplicação de herbicidas executadas pelo método manual e roçada pelo método semimecanizado (Figura 1).

No plantio foi utilizada uma plantadora tubular equipada com bomba costal para armazenamento de hidrogel, com massa total de $28,9 \mathrm{~kg}$; na adubação, uma adubadora tipo catraca conectada a uma bomba costal para armazenamento do fertilizante, com massa total de 20,3 kg; na roçada, uma roçadora da marca Stihl modelo FS 220, com massa total de 7,7 kg; e na aplicação de herbicidas, uma bomba costal conectada por uma mangueira de pressão ao aspersor equipado com proteção tipo chapéu de napoleão, com massa total de $9,0 \mathrm{~kg}$.

\subsection{População e amostragem}

A população pesquisada foi composta por uma amostra de 72 trabalhadores florestais, selecionados aleatoriamente, sendo estudados 22 que atuavam no plantio, 18, na adubação, 27, na aplicação de herbicidas e cinco na roçada, representando $28,8 \%$ do total de trabalhadores da empresa.

Inicialmente, todos os trabalhadores participantes receberam esclarecimentos sobre a metodologia a ser aplicada e os objetivos da pesquisa, por meio da leitura e assinatura do Termo de Consentimento Livre e Esclarecido (TCLE), em atendimento à Resolução n. 466/2012 do Conselho Nacional de Saúde do Ministério da Saúde (BRASIL, 2012).

\subsection{Coleta de dados}

O levantamento dos fatores humanos e das condições de trabalho foi realizado por meio de questionários individuais aplicados aos trabalhadores na forma de entrevistas no próprio local de trabalho.

Foi utilizado um questionário desenvolvido pelos autores, que abordou dados sobre o perfil dos trabalhadores (idade, peso, estatura, escolaridade, origem, estado civil, número de filhos, moradia, experiência na função, vícios e hábitos), sendo as medidas de massa corporal e estatura obtidas com uso de balança e régua antropométrica. Foram ainda levantadas diversas questões relacionadas às condições de trabalho, contemplando aspectos gerais do trabalho, alimentação, segurança, saúde e treinamento.
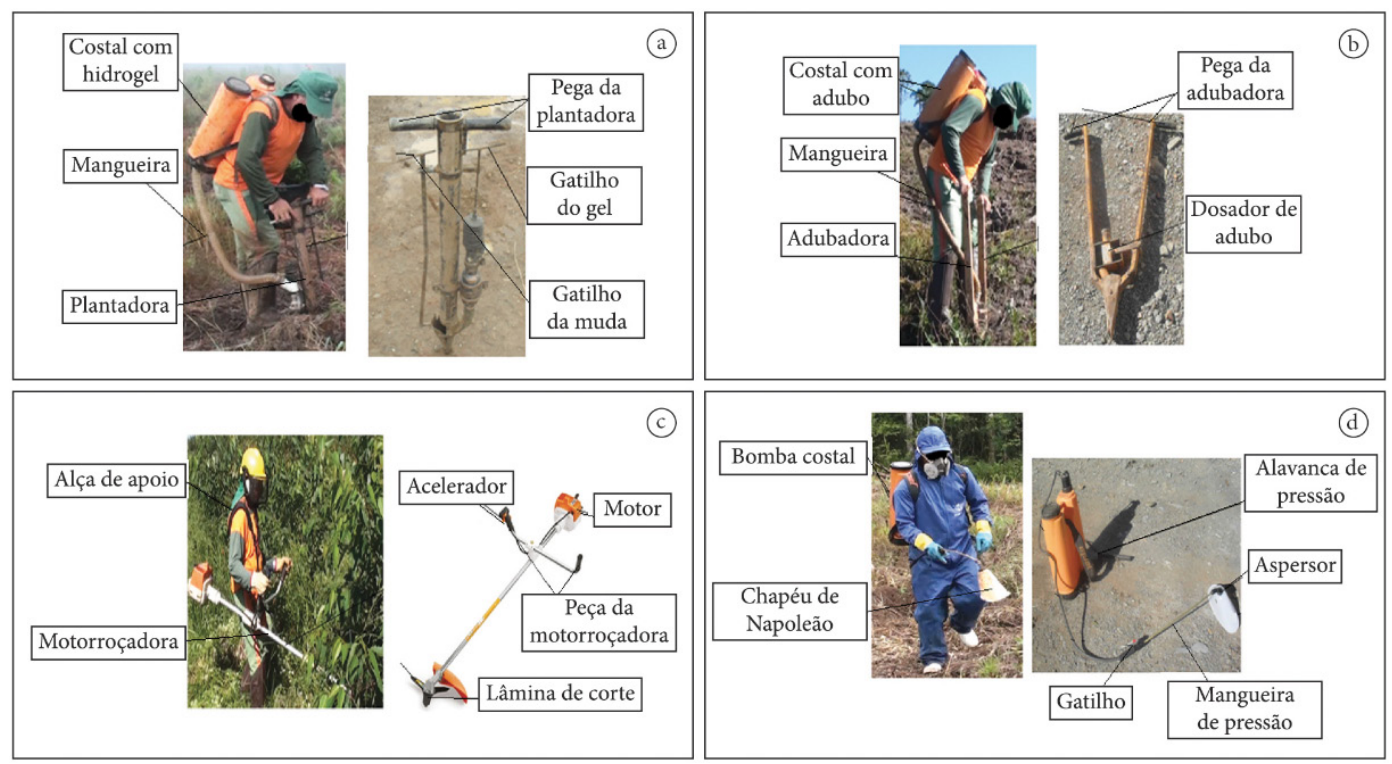

Figura 1. Atividades de implantação e manutenção florestal estudadas; (a) Plantio; (b) Adubação; (c) Roçada; (d) Aplicação de herbicida.

Figure 1. Forest maintenance and planting operations studied. 


\section{RESULTADOS E DISCUSSÃO}

\subsection{Fatores humanos relacionados ao trabalho}

Na Tabela 1 estão apresentados os resultados médios referentes aos fatores humanos dos trabalhadores que atuavam nas atividades de plantio, adubação, roçada e aplicação de herbicidas.

A média de idade dos trabalhadores que atuavam nas atividades estudadas foi 34,9 anos, sendo que na adubação e plantio estão os trabalhadores de maior idade, com 37,8 e 35,2 anos, respectivamente. Os valores obtidos estão acima daqueles encontrados por Lopes et al. (2011) para trabalhadores florestais da Região Norte Pioneiro do Paraná (31,7 anos) e semelhante aos obtidos por Ferreira (2006) também para trabalhadores de implantação florestal em Minas Gerais (34,5 anos).

A estatura $(1,67)$ e a massa corporal $(69,3)$ médias dos trabalhadores foram semelhantes aos valores encontrados por Silveira (2006) em trabalhadores de implantação florestal, com $1,70 \mathrm{~cm}$ e massa corporal de $68,8 \mathrm{~kg}$.

Os resultados mostraram ainda que, a maioria dos trabalhadores estudados $(52,2 \%)$ eram casados, principalmente os que atuavam nas atividades de plantio, adubação e aplicação de herbicidas, enquanto o percentual de trabalhadores solteiros era de $14,6 \%$. O número médio de filhos foi de 1,8 filho por trabalhador, valor inferior ao encontrado por outros autores como Minetti (1996), Fiedler (1998) e Silveira
(2006), que obtiveram em seus estudos valores de 2,8, 3,0 e 2,0 filhos, respectivamente.

O baixo número de filhos foi justificado pelos entrevistados como sendo uma tendência atual das famílias brasileiras, ocasionada principalmente pelas questões financeiras que limitam a manutenção de uma família com maior número de filhos, o que demonstra a conscientização dos trabalhadores florestais em relação às questões familiares.

A maioria dos trabalhadores estudados (77,5\%) possuía apenas o ensino fundamental incompleto, podendo os resultados estar relacionados com sua origem rural $(89,3 \%)$ e pelo fato de a maioria ter interrompido precocemente os seus estudos pela necessidade de ingressar no mercado de trabalho. Tal resultado comprovou que, normalmente, esse tipo de trabalho é executado por pessoas com baixo grau de instrução e de origem rural, acostumados às condições de trabalho severas no campo e sem maiores oportunidades no mercado de trabalho.

A maioria dos trabalhadores eram destros (80,6\%), destacando-se os que atuavam nas atividades de plantio, adubação e aplicação de herbicidas, com 86,4\%, 83,3\% e $92,6 \%$ dos entrevistados, respectivamente. Tal resultado é muito importante para auxiliar os gestores florestais na execução de programas de treinamento e no desenvolvimento de máquinas e ferramentas adaptadas às necessidades antropométricas de cada trabalhador.

Em relação ao tempo de serviço na empresa e na função, verificou-se que os trabalhadores atuavam, em média, há 14,9 e 12,5 meses, respectivamente. Pelos resultados obtidos, verifica-se que as atividades de

Tabela 1. Fatores humanos relacionados aos trabalhadores nas atividades estudadas.

Table 1. Human factors related to workers in the activities studied.

\begin{tabular}{lcccccc}
\multirow{2}{*}{\multicolumn{1}{c}{ Características analisadas }} & \multicolumn{5}{c}{ Valores médios } \\
\cline { 2 - 6 } Idade (anos) & Plantio & Adubação & Roçada & Herbicida & Média \\
\hline Estatura (m) & 35,2 & 37,8 & 32,4 & 34,4 & 34,9 \\
Massa corporal (kg) & 1,69 & 1,68 & 1,64 & 1,66 & 1,67 \\
\hline Estado civil (\% casados) & 70,5 & 68,1 & 67,9 & 70,8 & 69,3 \\
\hline Número de filhos (média) & 68,2 & 61,1 & 20,0 & 59,3 & 52,2 \\
\hline Escolaridade (\% fundamental incompleto) & 2,1 & 1,9 & 1,6 & 1,6 & 1,80 \\
\hline Possuidores de casa própria (\%) & 72,7 & 72,2 & 80,0 & 85,2 & 77,5 \\
\hline Destreza manual (\% destros) & 90,9 & 77,8 & 100,0 & 77,8 & 86,6 \\
Origem rural (\%) & 86,4 & 83,3 & 60,0 & 92,6 & 80,6 \\
\hline Tempo na empresa (meses) & 95,5 & 88,9 & 80,0 & 92,6 & 89,3 \\
\hline Tempo na função (meses) & 20,9 & 8,4 & 5,0 & 25,4 & 14,9 \\
\hline
\end{tabular}


aplicação de herbicidas e plantio foram aquelas em que os trabalhadores possuíam maior tempo de serviço na empresa e na função, com valores de 25,4 e 20,9 meses e de 19,9 e 17,1 meses, respectivamente, sendo, portanto, as atividades mais antigas executadas por esses trabalhadores na empresa estudada.

É importante ressaltar que o baixo tempo de serviço dos trabalhadores na empresa e na função podem estar relacionados ao fato do pouco tempo de atuação da empresa como prestadora de serviços na região. Além disso, percebe-se haver uma baixa rotatividade de funções, porém esperada, devido ao pouco tempo de atuação da empresa e dos trabalhadores nas atividades. Por outro lado, os resultados mostram haver uma tendência de permanência dos trabalhadores na mesma função, que segundo Fiedler et al. (2001) é uma situação preocupante devido ao fato de os trabalhadores não terem oportunidades de ascensão profissional dentro da empresa, gerando uma expectativa negativa, principalmente dentre os recém-contratados.

Em relação à jornada de trabalho, os trabalhadores atuavam em média oito horas diárias, de segunda à sexta-feira. $\mathrm{O}$ tempo médio de viagem da sede da empresa ao local de trabalho durante a realização do estudo foi de uma hora, porém sendo normalmente variável em função da localização das fazendas e da programação das atividades a serem executadas no decorrer do ano. É importante destacar que a empresa pagava aos trabalhadores o tempo consumido com o transporte, denominado hora itinere, conforme estabelecido pelo sindicato da categoria em convenção coletiva.

\subsection{Condições de trabalho}

\subsubsection{Condições gerais}

Ao analisar as condições gerais de trabalho, constatou-se que apenas $11,5 \%$ do total de entrevistados manifestaram interesse em mudar de função dentro da empresa, com destaque para os trabalhadores da aplicação de herbicidas (37\%), podendo ser explicado pela maior conscientização desses em relação à periculosidade da atividade e pelo elevado esforço físico demandado.

Quando questionados em relação aos motivos que os levaram a ter escolhido a função que desempenhavam, $40,8 \%$ dos trabalhadores relataram ser por falta de outras oportunidades de trabalho na região, 19,7\%, por gostarem desse tipo de trabalho, $15,5 \%$ devido ao melhor salário oferecido pela empresa e 12,6\% pela experiência na função. Tal resultado demonstra a importância da empresa como fonte empregadora para a região na época da realização do estudo.

Em relação ao desgaste físico no trabalho, $81,1 \%$ dos entrevistados consideraram o trabalho moderado, $11,3 \%$, pesado e $6,5 \%$, leve, ressaltando ainda o fato de que $68,8 \%$ dos entrevistados afirmaram sentir muito cansaço físico após a realização do trabalho. Tal afirmação, segundo os entrevistados, deve-se aos constantes deslocamentos no decorrer da jornada de trabalho e das condições ambientais desfavoráveis, situações comuns durante a execução das atividades silviculturais.

A Figura 2 apresenta os dias da semana de maior e menor produtividade, de acordo com a percepção dos trabalhadores. Para 34,7\% dos entrevistados não há diferença de produtividade entre os dias da semana, sendo que as condições locais, principalmente as irregularidades do terreno, foram apontadas como fator que pode ocasionar alterações na produtividade. Por outro lado, 65,3\% relataram haver diferença, sendo que as segundas e sextas-feiras foram apontadas como os dias de menor produtividade. Tal informação é importante, pois a empresa poderá utilizar esses dias da semana para a realização de pagamentos, palestras, cursos e treinamentos.

\subsubsection{Costumes e vícios}

Com relação aos costumes e vícios, os resultados mostraram que $30,1 \%$ dos trabalhadores estudados afirmaram fazer uso do fumo, consumindo em média, 15 cigarros diários, situação que poderá influenciar negativamente o desempenho no trabalho e as condições de saúde dos trabalhadores. Tal valor foi

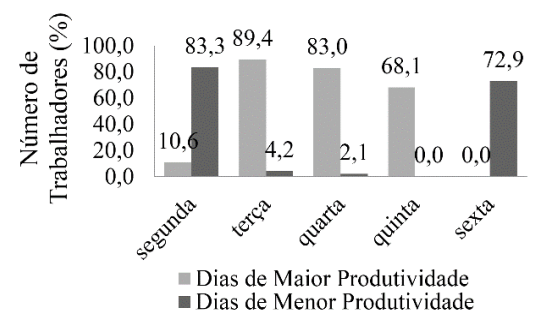

Figura 2. Representação dos dias da semana de maior e menor produtividade.

Figure 2. Representation of the weekdays of higher and lower productivity. 
inferior ao obtido por Fiedler (1998), com 37,8\%, Ferreira (2006), com 50,0\%, e Silveira (2006), com $30,4 \%$ dos trabalhadores florestais que também faziam uso do fumo. Tal redução de fumantes demonstra certa conscientização dos trabalhadores em relação aos efeitos maléficos do tabaco.

De acordo com o Instituto Brasileiro de Geografia e Estatística - IBGE (2013), a média brasileira de fumantes é de 17,5\%, podendo chegar a 20,4\% entre os brasileiros que vivem na área rural e a 25,0\% entre os menos escolarizados, sendo comum o consumo diário de 15 a 24 cigarros.

Em relação às horas de sono, os entrevistados informaram que, em média, dormiam 7,0 horas diárias, período considerado suficiente para $66,8 \%$ dos entrevistados. No plantio e na roçada, $81,8 \%$ e $80,0 \%$, dos trabalhadores consideravam o período de sono suficiente, enquanto na aplicação de herbicidas e na adubação apenas 55\% e 50\% dos trabalhadores consideraram o tempo suficiente, respectivamente. Muitos trabalhadores informaram que compensavam o cansaço e a insuficiência de sono durante o período do transporte realizado entre sua residência e as fazendas da empresa.

\subsubsection{Aspectos de saúde}

Em relação às questões de saúde, todos os entrevistados inicialmente relataram possuir o hábito de beber água durante a jornada de trabalho, sendo ingeridos, em média, 3 litros diariamente. A água era transportada em garrafas térmicas fornecidas pela empresa e sua origem, a residência dos próprios trabalhadores.

Com relação à alimentação, a empresa fornecia aos trabalhadores café da manhã, composto de dois pães, café puro ou café com leite. $\mathrm{O}$ almoço era fornecido por uma empresa terceirizada em recipientes tipos marmitex, armazenados em uma caixa térmica para manter a qualidade e temperatura dos alimentos, dentro dos limites aceitáveis pela Agência Nacional de Vigilância Sanitária (BRASIL, 2014). O cardápio era variável, composto por feijão, arroz ou massa, carne vermelha ou branca, guarnição como farofa ou legumes cozidos, salada e refrigerante ou suco, além de um doce ou fruta como sobremesa.

Os trabalhadores faziam suas refeições em locais adequados nas frentes de trabalho, denominadas Áreas de Vivência, conforme determina a Norma
Regulamentadora de Segurança e Saúde no Trabalho na Agricultura, Pecuária, Silvicultura, Exploração Florestal e Aquicultura - NR-31 (Segurança e Medicina do Trabalho, 2009). Esses locais possuíam barracas de lonas equipadas com banquetas dobráveis, lixeira com separação de resíduos e instalações sanitárias.

As instalações sanitárias eram de lona, possuindo vaso sanitário e papel higiênico, lavatório com água, detergente e toalhas descartáveis. Alguns trabalhadores informaram não fazer uso regular do vaso sanitário por falta de hábito, constrangimento em relação aos colegas, enquanto muitos consideraram o espaço interno reduzido. Tal posicionamento dos trabalhadores foi muito importante, pois mostrou a necessidade de uma revisão da Norma NR-31, necessitando que sejam especificadas claramente as dimensões das instalações sanitárias pois, atualmente, tal norma especifica apenas a proporção de número de vasos sanitários por quantidade de usuários.

Com relação aos problemas de saúde, a maioria dos entrevistados (97,5\%) afirmou não ter tido problemas de saúde ocasionados pelas atividades que exerciam nos últimos tempos. Porém, ao serem questionados se permaneceram algum tempo sem trabalhar por motivo de doença, $18 \%$ dos entrevistados do plantio e $11 \%$ dos da aplicação de herbicidas informaram que se ausentaram do trabalho por motivo de doença. Entre os principais motivos alegados estão dores no intestino e estômago, cirurgias médicas ou dentárias, resfriados e intoxicação por herbicidas, sendo esse último caso relatado pelo próprio trabalhador, ocasionado por descuidos no momento da execução do trabalho.

Além disso, ressalta-se o fato de que 11,7\% dos trabalhadores acusaram sentir desconforto na visão, explicado pelo maior esforço visual durante a execução do trabalho, sendo relatado por $22,2 \%$ dos trabalhadores da aplicação de herbicidas, seguidos pelos trabalhadores do plantio e adubação, com 13,6 e 11,1\%, respectivamente. O elevado percentual de trabalhadores da aplicação de herbicidas com desconforto na visão pode ser justificado pelos óculos de proteção utilizados na atividade, que são transparentes, sem proteção contra a incidência de raios solares.

Portanto, tal resultado mostra a necessidade de melhoria da qualidade dos óculos de proteção utilizados pelos trabalhadores, bem como o fornecimento de óculos escuros que protejam os demais trabalhadores 
dos raios solares, pois as atividades de implantação e manutenção florestal normalmente são realizadas em campo aberto e com a presença de intensa insolação e reflexos muitas vezes incômodos.

Por fim, 4,4\% dos entrevistados afirmaram sentir alguma dificuldade de audição quando se encontram fora do ambiente de trabalho, enquanto apenas 1,9\% relataram sentir dores de ouvido e $2,3 \%$, problemas respiratórios.

\subsubsection{Segurança no trabalho}

Em relação à segurança no trabalho, 19,3\% dos entrevistados informaram ter sofrido algum acidente de trabalho em sua vida profissional, sendo as pernas, mãos, cabeça e costas, as partes do corpo mais atingidas. Os motivos dos acidentes de trabalho mais relatados foram descuido na execução do trabalho, falta de conhecimento da operação, falta de uso dos EPIs, presença de obstáculos no local de trabalho e cansaço físico.

As principais periculosidades do trabalho na percepção dos trabalhadores eram a presença de resíduos no local de trabalho que dificultavam a realização das atividades e causavam riscos de quedas e lesões; a ocorrência de animais peçonhentos, que mesmo sem nenhum relato de acidente eram uma preocupação constante dos trabalhadores; e o manuseio de produtos tóxicos por ocasião da aplicação dos herbicidas, considerados extremamente prejudiciais quando manuseados sem os devidos cuidados e sem o uso de equipamentos de proteção, mostrando a conscientização dos trabalhadores em relação aos perigos do trabalho florestal.

É importante ressaltar que todos os Equipamentos de Proteção Individual (EPIs) necessários ao trabalho eram fornecidos pela empresa, sendo as reposições realizadas semanalmente, de acordo com as necessidades de cada equipe. Todos os entrevistados informaram ser necessário e concordavam utilizar os EPIs durante o trabalho.

Os EPIs comuns a todos os trabalhadores eram: coturno ou bota de couro com biqueira de aço, perneiras, boné com proteção de tecido (tipo árabe), luvas e uniforme com camiseta de algodão de manga comprida. A equipe da roçada utilizava ainda um capacete com viseira e protetor auricular tipo concha, enquanto a equipe de herbicidas possuía macacão impermeável, bota de borracha com palmilha de aço, luvas de borracha, óculos e máscara.
Do total de trabalhadores entrevistados, $47,2 \%$ relataram que os EPIs causavam incômodos no trabalho. Considerando a avaliação por atividade, a equipe de adubação $(88,9 \%)$ foi a que apresentou um maior índice de relatos de incômodo causado pelos EPIs, seguida da equipe dos herbicidas (48,1\%), da da roçada (40\%) e da do plantio (13\%).

As maiores reclamações de incômodo foram em relação a máscara, óculos e macacão utilizados na aplicação de herbicidas, sendo relatado principalmente pelos trabalhadores da adubação, que em muitas ocasiões atuavam também na aplicação de herbicidas e não estavam acostumados com o uso desse tipo de equipamento de proteção.

Em relação aos aspectos de segurança dos equipamentos e ferramentas utilizados na execução das atividades, a maioria dos entrevistados (88\%) afirmou sentir-se seguro no trabalho e consideraram todos de fácil manuseio. Entretanto, esses trabalhadores indicaram o peso das ferramentas, ocasionado pelos insumos utilizados, como um fator prejudicial.

Além disso, muitos trabalhadores informaram que podem regular a quantidade de insumos, porém a redução na quantidade ocasiona maior deslocamento dos trabalhadores devido aos frequentes reabastecimentos necessários ao longo da jornada de trabalho, com consequente cansaço físico.

Os trabalhadores que atuavam na adubação indicaram a mangueira de escoamento do fertilizante como um fator prejudicial à execução da atividade, em função de a mesma estar posicionada de maneira inadequada, causando o enroscamento e desconexão da ferramenta. Nesse aspecto foi sugerido pelos próprios trabalhadores a alteração no posicionamento da conexão da mangueira, que deveria situar-se na lateral da ferramenta.

Além disso, muitos trabalhadores informaram que o chapéu de Napoleão que se encontrava instalado na alça do aplicador de herbicidas com a finalidade de minimizar a deriva do produto químico durante a operação era um item pesado e que prejudicava a operação, causando maior cansaço físico aos trabalhadores.

\subsubsection{Treinamento}

Com relação ao treinamento, $100 \%$ dos trabalhadores informaram que participaram da atividade de integração realizada pelo setor de segurança da empresa, que repassava todas as informações sobre as características 
de cada atividade e dos procedimentos de segurança a serem adotados no trabalho. Além disso, no início de cada jornada de trabalho, os líderes das equipes de campo repassavam os procedimentos operacionais referentes às atividades que seriam executadas naquele dia de trabalho.

Quando os trabalhadores foram questionados se gostariam de receber novos treinamentos para aperfeiçoar as técnicas de trabalho, todos os entrevistados responderam afirmativamente. Tal resultado demonstra o importante papel que o treinamento exerce sobre o trabalhador e o interesse deles em melhorar a execução de sua função. Além disso, ao serem questionados sobre a oferta de treinamento em higiene do trabalho e primeiros socorros, todos responderam ter conhecimentos básicos, porém que gostariam de adquirir novos conhecimentos.

\section{CONCLUSÕES}

Em função dos resultados obtidos nesta pesquisa, chegou-se às seguintes conclusões:

a) Os trabalhadores florestais estudados foram caracterizados como de origem rural, casados, com baixo nível de escolaridade e com pouco tempo de experiência na empresa e na função.

b) A aplicação de herbicidas foi a atividade em que os trabalhadores demonstraram maior interesse em mudar de função, explicado pela periculosidade no manuseio de produtos químicos e maior esforço físico, sugerindo a necessidade de mecanização da atividade.

c) O pouco uso das instalações sanitárias pelos trabalhadores devido às suas dimensões inadequadas mostrou a necessidade de revisão da norma regulamentadora do Ministério do Trabalho, visando estabelecer medidas que proporcionem maior conforto aos trabalhadores.

d) Os óculos de proteção utilizados na aplicação de herbicidas foram mencionados como o maior causador de incômodo no trabalho e ineficiência na proteção contra a incidência de raios solares, comuns nas atividades silviculturais.

e) Os trabalhadores apontaram que a adubadora e o aplicador de herbicida apresentam problemas que podem prejudicar a execução do trabalho, necessitando os fabricantes alterarem o seu projeto original.

\section{AGRADECIMENTOS}

Os autores agradecem o apoio da empresa na cessão da área de estudo e ao CNPq pelo apoio financeiro.

\section{STATUS DA SUBMISSÃO}

Recebido: 29 jul., 2013

Aceito: 21 mar., 2015

\section{AUTOR(ES) PARA CORRESPONDÊNCIA}

\section{Eduardo da Silva Lopes}

Departamento de Engenharia Florestal, Universidade Estadual do Centro-Oeste UNICENTRO, CEP 84500-000, Irati, PR, Brasil e-mail: eslopes@pq.cnpq.br

\section{APOIO FINANCEIRO}

\section{CNPq.}

\section{REFERÊNCIAS}

Brasil. Ministério da Saúde. Conselho Nacional de Saúde. Resolução $n^{\circ} 466$, de 12 de dezembro de 2012. Diário Oficial da República Federativa do Brasil. Brasília, DF (2012 dez.). [citado em 2013 jul. 30]. Disponível em: http:// www.conselho.saude.gov. br/resolucoes/2012/Reso466.pdf

Brasil. Ministério da Saúde. Agência Nacional de Vigilância Sanitária. Resolução RDC $n^{\circ} 52$ de 29 de setembro de 2014. Altera a Resolução RDC $n^{\circ} 216$, de 15 de setembro de 2004, que dispõe sobre o Regulamento Técnico de Boas Práticas para os Serviços de Alimentação. Diario Oficial da República Federativa do Brasil, Brasilia, DF; 2014 [citado em 2015 jun. 24]. Disponível em: http://portal. anvisa.gov.br/ wps/wcm/connect/4da6088045b274f1a bclafa9166895f7/ RDC+52-2014+-+altera+RDC+216. pdf?MOD=AJPERES

Ferreira PC. Avaliação ergonômica de algumas operações florestais no município de Santa Bárbara, $M G$ [dissertação]. Caratinga, MG: Centro Universitário de Caratinga; 2006.

Fiedler NC, Venturoli F, Minetti LJ, Vale AT. Diagnóstico de fatores humanos e condições de trabalho em marcenarias no Distrito Federal. Revista Floresta 2001; 31(1-2): 105-113.

Fiedler NC. Análise de posturas e esforços despendidos em operação de colheita florestal no litoral do estado da Bahia [tese]. Viçosa, MG: Universidade Federal de Viçosa; 1998. 
Fontana G, Seixas F. Avaliação ergonômica do posto de trabalho de modelos de forwarder e skidder. Revista Árvore 2007; 31(1): 71-81. http://dx.doi.org/10.1590/ S0100-67622007000100009.

Grandjean E. Fitting the task to the man: an ergonomic approach. London: Taylor \& Francis; 1982. 379 p.

Iida I. Ergonomia: projeto e produção. 2. ed. São Paulo: Edgard Blücher; 2005. 630 p.

Instituto Brasileiro de Geografia e Estatística - IBGE. [online]. [citado em 2013 jun. 10]. Disponível em: www. ibge.gov.br

Lopes ES, Vosniak J, Fiedler NC, Inoue MT. Análise dos fatores humanos e condições de trabalho em operações de implantação florestal. Revista Floresta 2011; 41(4): 707-714. http://dx.doi.org/10.5380/rf.v41i4.25336.

Lopes ES. Diagnóstico do treinamento de operadores de máquinas na colheita florestal [dissertação]. Viçosa: Universidade Federal de Viçosa; 1996.

Massad MD, Leite AMP, Dutra TR. Fatores ergonômicos relacionados à saúde e à segurança em trabalhadores de um viveiro florestal. In: $V$ Workshop de Análise Ergonômica do trabalho e II Encontro Mineiro de Estudos em Ergonomia; 2011; Viçosa. Viçosa: Universidade Federal de Viçosa; 2011.
Minetti LJ, Souza AP, Machado CC, Fiedler NC, Baêta FC. Avaliação dos efeitos do ruído e da vibração no corte florestal com motoserra. Revista Árvore 1998; 22(3): 325-330.

Minetti LJ. Análise de fatores operacionais e ergonômicos na operação de corte florestal com motosserra [tese]. Viçosa: Universidade Federal de Viçosa; 1996.

Moreira NC. Qualidade de vida no trabalho: um estudo de caso na Universidade Federal de Viçosa [monografia]. Viçosa: Universidade Federal de Viçosa; 2009.

Sant’Anna CM, Malinovski JR. Análise de fatores humanos e condições de trabalho de operadores de motosserra de Minas Gerais. Cerne 2002; 8(1): 115-121.

Segurança e Medicina do Trabalho. NR 31- Norma regulamentadora de segurança e saúde no trabalho na agricultura, pecuária, silvicultura, exploração florestal e aquicultura. 4. ed. São Paulo: Saraiva; 2009. 974 p.

Silveira FSA. Avaliação ergonômica das atividades de coveamento manual, coveamento semimecanizado, plantio manual e aplicação de corretivo do solo na implantação florestal de eucalipto [dissertação]. Caratinga: Centro Universitário de Caratinga; 2006. 